\title{
Surgical findings in cryptorchidism in children with Zika-related microcephaly: a case series
}

\author{
Rômulo A. L. de Vasconcelos ${ }^{3 *}$ (1), Ricardo A. A. Ximenes ${ }^{3,4}$, Adriano A. Calado ${ }^{3}$, Celina M. T. Martelli', \\ Andreia V. Gonçalves $s^{3,4}$, Elizabeth B. Brickley ${ }^{2}$, Thalia V. B. de Araújo ${ }^{4}$, Maria A. W. Rocha ${ }^{3}$ and Demócrito \\ de B. Miranda-Filho ${ }^{3^{*}}$
}

\begin{abstract}
Background: Complications in the urinary tract related to congenital Zika syndrome have recently been reported. One complication, cryptorchidism, has been reported by the Microcephaly Epidemic Research Group/MERG, in Pernambuco/Brazil. The present article describes for the first time the surgical findings in a case series of boys with Zikarelated microcephaly and cryptorchidism, who underwent surgical testicular exploration as a contribution to better understand the possible mechanisms involved in gonads formation and descent.

Methods: A total of 7 children (11 testicular units), aged 3 to 4 years, were submitted to inguinal or scrotal orchidopexy for the treatment of palpable cryptorchidism between August 2019 and January 2020. Characteristics of the gonads and its annexes related to appendixes, testis-epididymis dissociation, gubernacular insertion, and associated hydroceles and/or hernias were described. Measures in centimetres were taken for volume calculate.

Results: We found a low prevalence of testicular and epididymal appendix (66.7\%), a high prevalence of testisepididymis dissociation (55.6\%), low mean testicular volume for their ages (lower for older boys) and ectopic gubernacular insertion in all cases. There was no evidence of associated hydroceles and/or hernias in any case. No surgical complication was registered or reported, and all explored gonads were properly placed in the scrotal sac.

Conclusions: We herein describe the surgical findings of these children's orchidopexies and discuss the possible mechanisms of viral action in embryogenesis and postnatal growth and development of the testes and annexes. These children need to be followed over time due to the higher risk of testicular atrophy and malignancy. Surgical timing seems to be relevant to avoid loss of testicular volume.
\end{abstract}

Keywords: Congenital Zika syndrome, Cryptorchidism, Microcephaly, Zika virus, Orchiopexy, Surgery, Case series

\section{Background}

Although neurodevelopmental impairments and structural brain defects are amongst the most common features in children with Zika-related microcephaly (ZRM), the condition has also been increasingly associated with

\footnotetext{
*Correspondence: romulo.alv@hotmail.com; demofilho@gmail.com

${ }^{3}$ Universidade de Pernambuco, Rua Arnóbio Marques, 310 - Santo

Amaro, Recife, PE 50100-130, Brazil

Full list of author information is available at the end of the article
}

abnormalities across a range of organ systems [1]. It is now recognized that a high frequency of children with ZRM may present with cryptorchidism [2]. Cryptorchidism is known to be associated with testicular cancer, infertility, and hypogonadism [3]. Here, we provide the first report on the findings of testicular surgical exploration in a case series of 7 male children, aged 3 to 4 years, with ZRM and cryptorchidism participating in the Microcephaly Epidemic Research Group (MERG) Paediatric Cohort, in Pernambuco, Brazil (Study Protocol: 
http:/www.cpqam.fiocruz.br/merg/) [4]. As main objective to better understand the possible mechanisms involved in this syndrome and its influences over gonads formation and descent.

\section{Methods}

Between August/2019 and January/2020, a MERG paediatric urologist assessed 31 males with microcephaly (i.e., totalling 62 testicular units), using the criteria of the 2018 paediatric guidelines of the European Association of Urology, and the results have been previously described [5]. Twelve boys were diagnosed with true cryptorchidism $(36.4 \%)$, while a further eleven had retractile testes (35.4\%). Of the 12 boys identified as having cryptorchidism, eight underwent testicular surgical exploration. Five were operated on by a team of paediatric urologists from MERG, two by a paediatric surgeon from a private health service that was not part of the research group, and one by a paediatric surgeon at the same institution where follow-up of the MERG cohort is undertaken (NB: this child underwent surgery at age two and was subsequently recruited to the cohort, but was not included in this case series due to lack of information on surgical findings).

Laterality was defined during medical consultations by physical examination. The records regarding the aspect of the testes and annexes, gonadal volume, gubernacular insertion, and associated findings (hernias, hydroceles, and persistent peritoneal vaginal conduit) were obtained by in-surgery measurement and photographs taken by the research group during the surgical procedures. TED classification is confusing and not standardized, so it was classified in two groups: partial (head or tail attachment) or complete failure (even if attached to any structure distinct to the testis, like the gubernaculum) [6]. The location of the insertion of the gubernaculum was assessed by pulling at the gubernaculum and determining where the retraction occurred. Testicular volume was calculated using the formula: volume $\left(\mathrm{cm}^{3}\right)=0.523 \times$ length $\times$ height $\times$ width $(\mathrm{cm})$, while the volume expected for age was obtained from the formula: volume $\left(\mathrm{cm}^{3}\right)=0.004 \times($ age in months $)+0.438$ [7]. Data on the two children who underwent surgery in the private service were obtained through telephone contact with the responsible surgeon.

All parents/guardians signed an informed consent form. This study was approved by the Oswaldo Cruz Hospital Ethical Committee (CAAE: 94544518.2.0000.5192).

\section{Results}

Four children presented bilateral cryptorchidism with palpable gonads in the inguinal regions, two presented with palpable cryptorchidism in the left inguinal region only, and the last presented with palpable cryptorchidism in the right inguinal region only. In all cases, either inguinal or scrotal testicular exploration was performed. In one patient with bilateral cryptorchidism, exploration of the right side was not undertaken due to the occurrence of respiratory distress, which led us to curtail the surgery, following the recommendation of the anaesthesiologist. Following surgery, the child developed febrile illness, which was attributed to a respiratory viral infection, but went on to fully recover. In one of the patients with bilateral cryptorchidism submitted to surgery in the private service, exploration on the left side was not undertaken, as the attending physician decided that the surgery should be undertaken in two steps. In total, nine testes were submitted to orchidopexy. None of the children experienced complications related to surgical manipulation (Table 1).

Table 1 Characterization of a case series of cryptorchidism in children with ZRM submitted to surgical exploration

\begin{tabular}{|c|c|c|c|c|c|c|}
\hline Patient & $\begin{array}{l}\text { Age } \\
\text { at surgery } \\
\text { (years) }\end{array}$ & Laterality & Aspect on surgical exploration & Volume $\left(\mathrm{cm}^{3}\right)$ & Gubernacular insertion & Associated findings \\
\hline 1 & 3 & Right & Normal & Missing & Pubic & Absence \\
\hline 2 & 3 & Left & TED & 0.53 & Pubic & TA \\
\hline 3 & 3 & Bilateral & TED (both) & $\begin{array}{l}\text { Right: } 0.53 \\
\text { Left: } 0.56\end{array}$ & Pubic (both) & TA (both) \\
\hline 4 & 4 & Bilateral & $\begin{array}{l}\text { Right: not operated } \\
\text { Left: TED }\end{array}$ & $\begin{array}{l}\text { Right: not operated } \\
\text { Left: } 0.51\end{array}$ & $\begin{array}{l}\text { Right: not operated } \\
\text { Left: pubic }\end{array}$ & $\begin{array}{l}\text { Right: not operated } \\
\text { Left: EA }\end{array}$ \\
\hline 5 & 3 & Bilateral & Normal (both) & $\begin{array}{l}\text { Right: } 0.48 \\
\text { Left: } 0.49\end{array}$ & Pubic (both) & $\begin{array}{l}\text { Right: EA } \\
\text { Left: absence }\end{array}$ \\
\hline 6 & 4 & Left & TED & 0.43 & Pubic & $\mathrm{TA}$ \\
\hline 7 & 4 & Bilateral & $\begin{array}{l}\text { Right: normal } \\
\text { Left: not operated }\end{array}$ & $\begin{array}{l}\text { Right: missing } \\
\text { Left: not operated }\end{array}$ & $\begin{array}{l}\text { Right: pubic } \\
\text { Left: not operated }\end{array}$ & $\begin{array}{l}\text { Right: absence } \\
\text { Left: not operated }\end{array}$ \\
\hline
\end{tabular}


Five testes (55.6\%) presented with testis-epididymis dissociation (TED), which was partial in one case and complete in the other four (Fig. 1). Among the testes of the children operated on 3-years of age with available data (Patients 2, 3, and 5), the mean testicular volume observed was $0.52 \mathrm{~cm}^{3}\left(0.48-0.56 \mathrm{~cm}^{3}\right)$, lower than the expected mean volume of $0.60 \mathrm{~cm}^{3}\left(0.58-0.63 \mathrm{~cm}^{3}\right)$. For the testes of the 4-year-old group with available data (Patients 4 and 6), the mean testicular volume was $0.47 \mathrm{~cm}^{3}\left(0.43-0.51 \mathrm{~cm}^{3}\right)$, lower than the mean expected volume of $0.62 \mathrm{~cm}^{3}\left(0.63-0.67 \mathrm{~cm}^{3}\right)$. In two children (Patients 1 and 7), it was not possible to obtain data for calculating testicular volume. The testicular appendix was identified in four units operated on (44.5\%) and in two epididymis $(22.2 \%)$. In the cases that underwent surgery by the MERG surgeons and in the two patients included from the private health service, there was no identification or reports of persistent peritoneum-vaginal canal, hydrocele, or hernia. In all five cases operated on by the MERG surgeons and in the two from the private service, the gubernaculum presented an ectopic insertion in the pubic region (Table 2).

\section{Discussion}

The surgical findings we presented in this paper provide additional information to our previously reported case series and enlightens the possible mechanisms related to this condition [2]. The occurrence of TED was very high in this group of boys ( 5 occurrences $-55.6 \%$ ), and was complete in 4 cases. The expected frequency of this anomaly is only $0.9 \%$ in normal children and up to $8 \%$ in patients with cryptorchidism [8]. In our series, none of the boys presented with abnormalities of the peritoneum-vaginal canal. Our children are comparable to
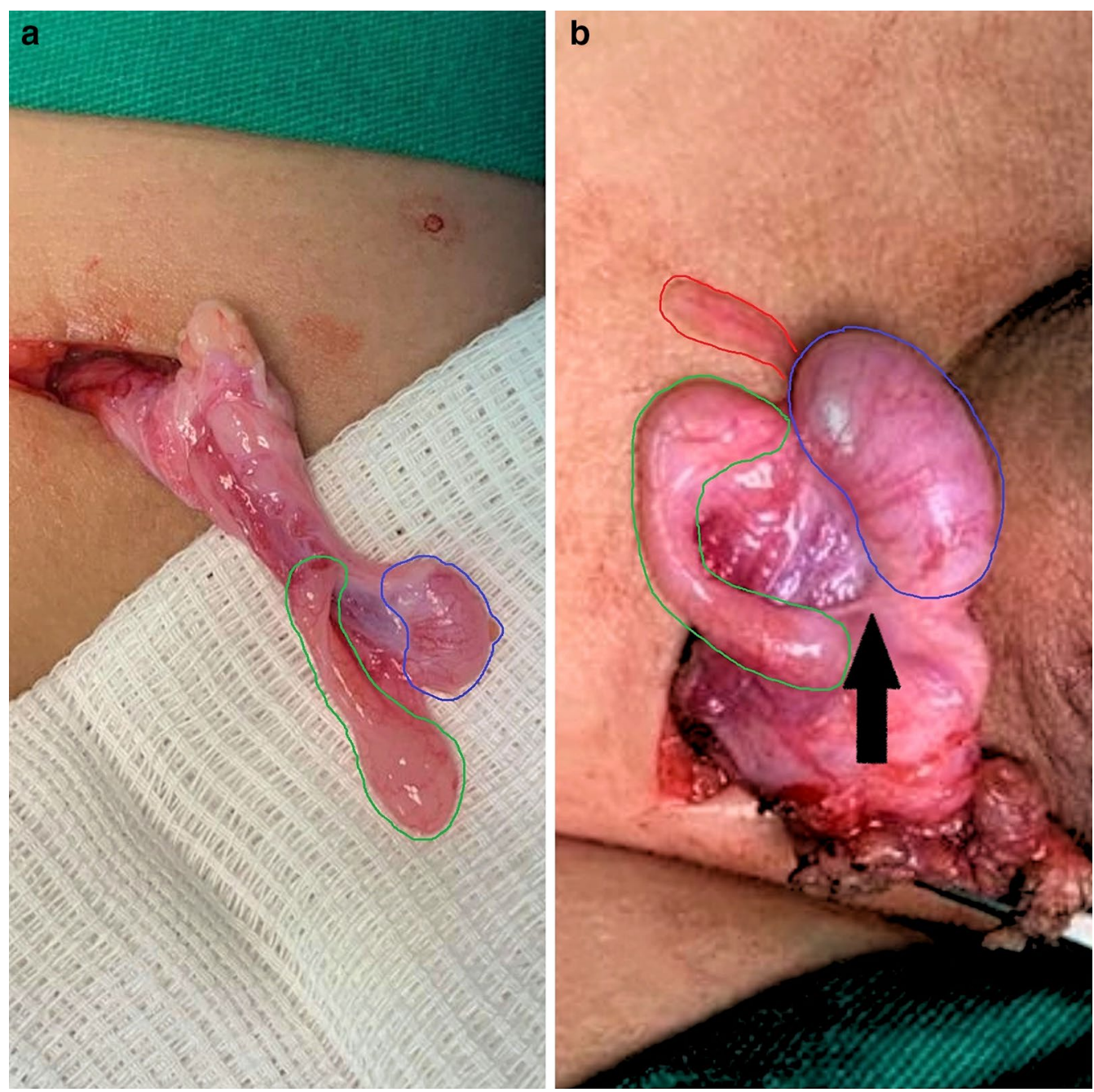

Fig. 1 a TED and testicular hypotrophy; b TED and epididymal appendix 


\begin{tabular}{|c|c|c|}
\hline \multicolumn{3}{|c|}{ Mean testicular volume ( $\mathrm{n}=9$ testicular units) } \\
\hline 3 years ( 5 testicular units) & $0.52 \mathrm{~cm}^{3}$ & $\left(0.48-0.56 \mathrm{~cm}^{3}\right)$ \\
\hline 4 years ( 2 testicular units) & $0.47 \mathrm{~cm}^{3}$ & $\left(0.43-0.51 \mathrm{~cm}^{3}\right)$ \\
\hline Missing & 2 & \\
\hline \multicolumn{3}{|c|}{ Testicular aspect ( $\mathrm{n}=9$ testicular units) } \\
\hline Normal & 4 & $44.4 \%$ \\
\hline TED & 5 & $55.6 \%$ \\
\hline \multicolumn{3}{|c|}{ Gubernacular insertion ( $n=9$ testicular units) } \\
\hline Pubic & 9 & $100 \%$ \\
\hline \multicolumn{3}{|c|}{ Associated findings ( $\mathrm{n}=9$ testicular units) } \\
\hline Absence & 3 & $33.3 \%$ \\
\hline Appendix testis & 4 & $44.5 \%$ \\
\hline Appendix epididymis & 2 & $22.2 \%$ \\
\hline
\end{tabular}

TED testis-epididymis dissociation

those of cerebral palsy in relation to brain damage and high frequency of undescended testicles $(36.4 \%$ in our children and $24 \%$ in children with cerebral palsy), however differ in relation to the frequency of inguinal hernias (none in our case series versus $56 \%$ in cerebral palsy) [2, 9].

Our understanding of the pathogenesis of cryptorchidism in children with ZRM is developing, and this case series provides findings that can help to better understand this physiopathologic process. Although the mechanisms of testicular descent are multi-factorial, given the high prevalence of TED and absence of anomalies of the peritoneum-vaginal conduit, it is plausible to suggest that congenital ZIKV infections should be considered as a possible explanation for the interferences on the formation mechanisms of the testis and epididymis during embryogenesis. Transmission of the Zika virus through the seminal fluid has been identified [10], which leads us to assume that there is a possible tropism of the virus to the gonadal and adnexal tissue. This possibility needs to be explored further in cadaver parts or testes submitted to orchiectomy. The frequency of gonadal appendix in our series (44.5\% in the testes and $22.2 \%$ in the epididymes) was lower than the reported by Zdizvic [11], who described a frequency of $78.7 \%$ in gonads located close to the external inguinal ring in 89 normal boys. All operated testes of our series were palpable close to the external inguinal ring. Testicular appendixes are remnants of the paramesonephric ducts, but their role in testicular descent has not been well established. The function of the gubernaculum, on the other hand, is to guide the descent of the testicles in the second phase (inguinoscrotal), through the action of testosterone and the genitofemoral nerve associated with abdominal pressure, and has been well documented [12]. The finding of 100\% ectopic gubernacular insertion in the pubic position could point this as being a possible mechanism responsible for the complete non-descent of these gonads and could also explain a lower, extra-abdominal location. The prevalence of ectopic gubernacular insertion in congenital cryptorchidism reported in the literature is low. Favorito [13] found no gubernacular ectopic insertion in 101 patients with cryptorchidism with a mean age of 6.4 years. Mejide Vries [14], describing surgical findings in congenital cryptorchidism in 76 testes, found $17 \%$ of gubernacular insertion in the bottom of the scrotum and $57 \%$ in the upper scrotum, totalling $74 \%$ scrotal gubernacular insertion. Due to their location, the non-descending gonads in the children with ZRM would be subjected to thermal stress, which could contribute to a progressive loss of testicular mass and volume. In this series, children operated at three years presented with abnormally low testicular volume, and the reduction in volume was even greater in children operated at four years. Delayed surgery (i.e., beyond the recommended maximum of 18 months of age) [5] may explain the lower testicular volume in the children with ZRM.

\section{Conclusions}

Our finding of a significant loss of testicular volume, attributed to late surgical correction, reinforces the importance of providing early attention to this anomaly. There is no apparent association with abnormalities of the peritoneum-vaginal canal, frequently seen in other children with cryptorchidism, even with cerebral palsy. The gubernaculum has an uncommon pubic insertion. A high frequency of TED calls attention to possible interference within gonadal formation, but further studies with a larger number of cases, histological examination and exploration of neuronal and hormonal abnormalities should be performed to better analyse these findings.

\section{Abbreviations}

ZRM: Zika-related microcephaly; MERG: Microcephaly Epidemic Research Group; TED: Testis-epididymis dissociation.

\section{Acknowledgements}

We extend our thanks to the Unipeclin/UPE and to the Zika virus research field team for helping with data collection and for providing support for the children and caregivers during their clinical consultations.

\section{Author contributions}

RALV: made substantial contributions to the conception, design of the work, acquisition, analysis, interpretation of data and has drafted the work. RAAX: made substantial contributions to the interpretation of data and has substantially revised it. AAC: made substantial contributions to the conception, design of the work and acquisition of data. CMTM: made substantial contributions to the interpretation of data and has substantially revised it. AVG: made substantial contributions to the interpretation of data and has substantially revised it. EBB: made substantial contributions to the interpretation of data and has substantially revised it. TVBA: made substantial contributions to the 
interpretation of data and has substantially revised it. MAWR: made substantial contributions to the interpretation of data and has substantially revised it. DBMF: made substantial contributions to the conception, design of the work, analysis, interpretation of data and has drafted the work. All authors read and approved the final manuscript.

\section{Funding}

This work was supported by the: European Union's Horizon 2020 Research and Innovation programme (https://ec.europa.eu/programmes/horizon202 0/) under ZikaPLAN grant agreement (No. 734584 to RAAX), (https://zikaplan. tghn.org/; Wellcome Trust \& the UK Department for International Development (201870/Z/16/Z to DBMF \& 205377/Z/16/Z to RAAX; https://wellc ome.ac.uk/); Wellcome Trust—Research Enrichment in Epidemic Situations (107779/Z/15/Z; with ER1505 \& ER1601 to RAAX); Medical Research Council on behalf of the Newton Fund and Wellcome Trust (MC_PC_15088; https:// mrc.ukri.org/); Fundação de Amparo à Ciência e Tecnologia de PE-FACEPE (APQ-0192-4.01/17 to Programa de Pós-graduação em Ciências da SaúdeUPE; https://www.facepe.br/); Coordenação de Aperfeiçoamento de Pessoal de Nível Superior-Brasil (CAPES)—Finance Code 001; Scholarship: Conselho Nacional de Desenvolvimento Científico e Tecnológico (309722/2017-9 to RAAX, 306708/2014-0 to CMTM; https://www.cnpq.br/), Secretaria de Vigilância em Saúde/ Ministério da Saúde de Brasil Resposta à Emergência em Saúde Pública_Zika vírus e Microcefalia (837058/2016 to RAAX); Conselho Nacional de Desenvolvimento Científico e Tecnológico, Coordenação de Aperfeiçoamento de Pessoal de Nível Superior (https://www.capes.gov.br/); Departamento de Ciência e Tecnologia (https://rebrats.saude.gov.br/notic ias/59DECIT) for Prevenção e Combate ao vírus Zika I (440839/2016-5 to RAAX). The funders had no role in study design, data collection and analysis, decision to publish, or preparation of the manuscript.

\section{Availability of data and materials}

The datasets used and/or analysed during the current study are available from the corresponding author on reasonable request.

\section{Ethics approval and consent to participate}

All parents/guardians signed an informed consent form. This study was approved by the Oswaldo Cruz Hospital Ethical Committee (CAAE: 94544518.2.0000.5192).

\section{Consent for publication}

All the parents/guardians gave their written consent for their child's personal or clinical details along with any identifying images to be published in this study. Written consents are available for consultation for legal or publishing purposes at any time. This study and consent form were previously approved by the Oswaldo Cruz Hospital Ethical Committee (CAAE: 94544518.2.0000.5192).

\section{Competing interests}

None of the authors have competing interest that could be perceived to bias this work.

\section{Author details}

${ }^{1}$ Instituto de Pesquisa Aggeu Magalhães - Fiocruz, Recife, Pernambuco, Brazil.

${ }^{2}$ London School of Hygiene and Tropical Medicine, London, UK. ${ }^{3}$ Universidade de Pernambuco, Rua Arnóbio Marques, 310 - Santo Amaro, Recife, PE 50100-130, Brazil. ${ }^{4}$ Universidade Federal de Pernambuco, Recife, Brazil.
Received: 29 May 2020 Accepted: 15 September 2020

Published online: 23 November 2020

\section{References}

1. Melo A, Aguiar R, Amorim M, et al. Congenital Zika virus infection. JAMA Neurol. 2016. https://doi.org/10.1001/jamaneurol.2016.3720.

2. de Vasconcelos R, Ximenes R, Calado A, et al. Cryptorchidism in children with Zika-related microcephaly. Am J Trop Med Hyg. 2020. https://doi. org/10.4269/ajtmh.19-0753.

3. Gurney J, McGlynn K, Stanley J, et al. Risk factors for cryptorchidism. Nat Rev Urol. 2017. https://doi.org/10.1038/nrurol.2017.90.

4. França G, Schuler-Faccini L, Oliveira W, et al. Congenital Zika virus syndrome in Brazil: a case series of the first 1501 livebirths with complete investigation. The Lancet. 2016. https://doi.org/10.1016/s0140 $-6736(16) 30902-3$.

5. Radmayr C, et al. EAU guidelines on paediatric urology. 2018. https:// uroweb.org/guideline/paediatric-urology/. Accessed 1 Feb 2020.

6. Qin K, Morley C, Nataraja R, Pacilli M. The spectrum of testicular-epididymal fusion anomalies in children with cryptorchidism: personal experience, systematic review and meta-analysis. J Pediatr Urol. 2020. https:// doi.org/10.1016/j.jpurol.2019.12.016.

7. Shin $\mathrm{H}$, Yoon $\mathrm{H}$, Lee Y, et al. Normal changes and ranges of pediatric testicular volume and shear wave elasticity. Ultrasound Med Biol. 2019. https://doi.org/10.1016/j.ultrasmedbio.2019.02.026.

8. Sharma S, Sen A. Complete testicular epididymal dissociation in the abdominal cryptorchid testis. J Pediatr Urol. 2013. https://doi. org/10.1016/j.jpurol.2013.02.017.

9. Barthold J, Wintner A, Hagerty J, Rogers K, Hossain M. Cryptorchidism in boys with cerebral palsy is associated with the severity of disease and with co-occurrence of other congenital anomalies. Front Endocrinol (Lausanne). 2018. https://doi.org/10.3389/fendo.2018.00151.

10. Mansuy J, Dutertre M, Mengelle C, et al. Zika virus: high infectious viral load in semen, a new sexually transmitted pathogen? Lancet Infect Dis. 2016. https://doi.org/10.1016/s1473-3099(16)00138-9.

11. Zvizdic Z, Zivkovic D, Sabanovic J, Milisic E. The role of the appendix testis in normal testicular descent: is there a connection? Biomed Res Int. 2018. https://doi.org/10.1155/2018/3078031.

12. Niedzielski J, Oszukowska E, Słowikowska-Hilczer J. Undescended testiscurrent trends and guidelines: a review of the literature. Arch Med Sci. 2016. https://doi.org/10.5114/aoms.2016.59940.

13. Favorito L, Klojda C, Costa W, Sampaio F. Is there a relationship with anomalous insertions of the distal gubernaculum testis and testicular ectopia? Analysis in human fetuses and patients with cryptorchidism. J Urol. 2003. https://doi.org/10.1097/01.ju.0000070436.98851.46.

14. Meij-de Vries A, Hack W, Heij H, Meijer R. Perioperative surgical findings in congenital and acquired undescended testis. J Pediatr Surg. 2010. https:// doi.org/10.1016/j.jpedsurg.2010.02.121.

\section{Publisher's Note}

Springer Nature remains neutral with regard to jurisdictional claims in published maps and institutional affiliations. 